\title{
Study on the Construction of Newly-Built Private Undergraduate University Application-Oriented Curriculum System
}

\author{
Jiangbo Chen \\ Qingdao Huanghai University \\ Qingdao, Shandong, China \\ jiangbochen1981@163.com
}

Shaoqing Wang

Qingdao Huanghai University

Qingdao, Shandong, China

\author{
Yan $\mathrm{Li}^{*}$ \\ Qingdao Economic \& Technological Development Area \\ No.2 Experimental Primary School \\ Qingdao, Shandong, China \\ liyanvsl@126.com
}

\author{
Shixian Zeng \\ Qingdao Huanghai University \\ Qingdao, Shandong, China
}

\begin{abstract}
The application-oriented curriculum system construction is important for the newly-built private undergraduate universities to cultivate technical talents, and a scientific curriculum system is the guarantee of the quality of personnel training. This paper expounds the basic idea of the construction of the applied curriculum system, takes the electromechanical integration in Qingdao Huanghai University as an example. This paper focuses on the theory, the curriculum goal, curriculum setting and the selection and organization of curriculum content; puts forward some ideas of curriculum provision for newly-built private undergraduate universities. Firstly, the paper analyzes the training program and learns the subject objectives with fully research of the talents requirement from the economic society and the industrial firms. Secondly, the paper analyzes the requirements of knowledge, skills and the attitude of the talents, and details the requirements into the curriculum. Thirdly, the paper makes clear the curriculum objectives, curriculum content, curriculum ways and curriculum evaluation.
\end{abstract}

Keywords-private undergraduate universities, applied talents, curriculum system, social demand

\section{INTRODUCTION}

The newly-built undergraduate universities have arisen under the background of higher education basification and have become the important part of higher education. The aim of higher education is to foster high skilled talents for manufacture, construction, service and management. Newlybuilt undergraduate universities should train the applied talents to highlight the professional ability and professional accomplishment, and also pay attention to social needs. Talent should meet industry needs and the update of regional industrial structure, to achieve higher education goals ultimately. Training the excellent person needs to take the curriculum as the essential way. Teaching activities should be based on curriculum plan as the main support. The content of the course should be transformed into students' quality and ability through curriculum, too. Obviously, the curriculum is the essential way to carry out the quality education.[1].

Applied undergraduate education is a new type of education, which is produced in the popularization of higher education. The key to the connotation construction of application-oriented universities is how to scientifically locate and highlight their own characteristics. As the main carrier to realize talents cultivation goal, curriculum is the core of connotation construction. For a long time, Universities in our country only emphasized the teaching of theoretical knowledge in the course setting, neglected the cultivation of practical knowledge or applied skills, which resulted that theoretical knowledge was out of step with the development of practical skills. Curriculum content lagged behind the needs of economic and social development, and curriculum structure was out of balance. In the era of higher education popularization, the malpractice of talent training mode is becoming more and more serious. In fact, the disadvantage of the pattern of talent training reflected above is becoming more and more serious in recent years. For example, college graduates "employment difficulties" and enterprises "labor shortage" contradiction phenomenon, it highlights this disadvantage.

The applied curriculum system is a concept relative to academic courses. Applied undergraduate education is different from the traditional academic undergraduate education. It is mainly committed to the cultivation of advanced applied talents of production, management, service. Therefore, the application-based curriculum model should be "another way", which needs to step out of the excessive dependence on the traditional academic curriculum model, which is constructed by the discipline system, and build a new "application-oriented" curriculum model. In this new curriculum model, both the subject knowledge and quality training can be organically integrated, It takes the real technical activity project as the clue, takes the ability training 
as the focal point, and supports the curriculum setting with the discipline knowledge[2].

\section{THE ORIENTATION OF CURRICULUM OBJECTIVE SHOULD BE CULTIVATING "PROFESSIONALS"}

The orientation of curriculum objective is the first step of curriculum design. Scientific and reasonable orientation has a very important guiding function to the following curriculum setting and curriculum content. The sources of curriculum objectives are diversified, including social needs, professional characteristics and international standards. In order to make the target clearer, we divide the course goal into the overall goal of the course plan, the specific curriculum goal and the teaching module goal.

The goal of the course plan refers to the overall intention of the whole course, and the goal of the training program in the talent training program is the goal of the professional curriculum.[3]. The goal of each course is only the completion of a particular section of the objectives of the curriculum. teaching objectives refers to the objectives of each teaching module, which is usually reflected in the lesson plan, and is a concrete description of the content of each course.

The differences of curriculum systems between academic and applied oriented undergraduate educations are compared, defining that the curriculum system of academic undergraduate education is centered on cultivating oriented talents with abundant theoretical knowledge and scientific research ability, while applied oriented undergraduate education is centered on cultivating technical talents with specific professional knowledge and practical ability. The differences of cultivation objectives result in large differences concerning curriculum contents, designs, implementations and evaluations between the two.

When Qingdao Huanghai University where the author works, develops electromechanical integration professional training program, teachers give full consideration to the content which should be efficient and practical, and should have continuity, so that the knowledge can be applied directly to the work process. The curriculum which is developed and evaluated according to the business tasks of the enterprise can reasonably locate, accurately grasp the enterprise demand, and develop the courses suitable for its actual situation according to the requirements and practical characteristics. The demands of social students should be fully known. For the courses in strong demand should be paid more attention.

According to the questionnaire survey of the talent needs of Qingdao moist Equipment Co., Ltd. and Qingdao Dongfang Huicheng Electronics Co., Ltd, and the survey of mechanical and electrical graduates of the school in recent years, through the holding of expert interviews and industry research, we extensively solicited the opinions and suggestions of industry and enterprise technical experts. According to the analysis of the corresponding professional jobs and posts, we summarize and sort out the typical tasks. According to the typical tasks, we determine the professional curriculum in the learning field. According to the characteristics of students and occupation growth law, we constructs the professional curriculum system of electromechanical application system. The curriculum system is centered on the cultivation of applied talents with certain professional knowledge and practical ability. From the vertical dimensions of the development of engineering scientists and technicians, we analyze the knowledge, ability, quality and business requirements of the new industrialization development, and sum up knowledge specification requirements at the core of a complete scientific knowledge structure, ability specification requirements at the core of outstanding engineering practices, quality specification requirements at the core of a strong sense of reform and innovation.

\section{THE CURRICULUM SHOULD MATCH WITH THE TRAINING OBJECTIVES}

Courses are important ways and means to achieve training objectives, while the curriculum is based on training objectives. It is the basic premise of curriculum setting to make clear the target of talent training. The so-called training goal is "what kind of person we want students to become". The curriculum is under the guidance of certain educational goals and training objectives, and is determined by the values of a certain education and curriculum. It is a series of practical activities that are planned by the school or the competent department of education according to the needs of students, society and subjects.

The study found that the overall structure of vocational education curriculum in our country is seriously imbalanced. The internal structure of the curriculum is unreasonable. The curriculum does not reflect the requirements of training objectives, and curriculum is still to be improved in terms of broadening students' knowledge and improving students' practical ability. It mainly manifested in that the theoretical courses are relative surplus but practical courses are seriously inadequate. And professional courses and public courses are also relative surplus. Elective Course categories are single and it is lack of educational elective courses. Practical courses are not practical. The practical courses of education have not been paid attention to. There is a lack of specialized teaching course. Therefore, the structure of higher education programs should be optimized, and disciplines of basic courses should be integrated. Professional courses should be appropriately reduced. Elective courses categories and weightings should be increased, and practical courses should be strengthened. Educational programs should be emphasized, and the creation of professional teaching methods courses should be increased. The course of specialized teaching theory should be set and the curriculum of educational practice should be paid attention to.

Economic and social development requires higher education to cultivate a wide range of expertise, namely training applied people. To cultivate applied people, on the basis of setting up the specialty, the application school must strengthen the connection between the professional courses and the professional standards, so that the talents trained in the universities meet the needs of the enterprises and the market. The curriculum should be guided by the regional economic development strategy and the requirements of the industry development, and take the important and whole course construction to the construction of the platform and module of 
practice oriented curriculum. Optimize the curriculum arrangement, introduce general education courses and increase practical training courses. It must reflect the school's adaptability to social and economic development, scientific and technological progress and professional position.

On the basis of theory, we must define that what should electromechanical integration curriculum system place more emphasis on or weaken, and how to integrate the curriculum to achieve the "technical goals" and "competency goals" training matrix expected by stakeholders, and then, from the three aspects of curriculum system design, curriculum system implementation and curriculum system evaluation, explore the construction of the project driven curriculum system, and provide reference and basis for the colleges and universities to form the curriculum system which takes the project as the main line, the teacher as the guide, the students as the main body, and the integration of technology and ability as the basic characteristics. We should increase the practical courses and class number, increase the number of required professional courses, which will optimize the professional basic courses. In the time and content of each course, we should take into account the needs of society and students, and make a reasonable proportion of the content of the course and the number of courses. In the end, the four main modules of classroom teaching have been formed, including the general vocational quality curriculum module, the professional basic vocational quality curriculum module, the specialized directional professional quality module and the developing vocational quality module, and an extracurricular activity curriculum module and an off campus practice and internship module, which form a curriculum system of vocational quality based education. Taking the mechatronics curriculum program of Qingdao Huanghai College as an example, we made a preliminary construction attempt.

\section{CURRICULUM CONTENT CONNECT WITH PROFESSIONAL STANDARDS}

Curriculum content is the materialization of curriculum objectives. It should make clear that what the relationship between each discipline and project is. When choosing the course content, we mainly consider the characteristics of students, the level of technological development, social needs, knowledge categories and other factors. Although some colleges and universities are implementing applied oriented undergraduate education, but they are influenced by traditional academic education. Therefore, there are some problems in current curriculum system, including the curriculum objectives lag behind the social needs, and can not highlight the characteristics of applied education. The value orientation of curriculum content is single, the content selection is affected, and the content allocation problem exists the curriculum design is vague and unclear; the design ability needs to be improved. The teaching method needs to be improved, and the integration between theoretical and practical teaching is poor. The method of examination is single, and the characteristics of application can not be highlighted. The teaching methods are backward, and the teaching quality evaluation methods need to be improved. Teaching methods are traditional and inquiry learning methods are difficult to popularize. The evaluation methods of teacher's teaching quality are more traditional, and they lack the evaluation of social, enterprise and other employers.

In recent years, China's Higher Education Curriculum reform has achieved great progress, especially the curriculum system based on the working process established according to the requirements of enterprise position and practical tasks. The curriculum system based on work process is built at the core of capacity-training, highlighting the adaptability of curriculum, the practicability of course content and the advance of teaching means, in order to train the professional quality and comprehensive capabilities of students. Curriculum content connects with professional standards, to build a curriculum system based on work process knowledge and core competence, determine the content of the course, and form a broader platform for development. Taking vocational standards into the formulation of curriculum content plays an important role in the development of curriculum reform in Modern Higher Vocational Colleges

At the same time, we must strengthen the cultivation of humane quality. The humane quality is the comprehensive system of world view, philosophy, cultivation and temperament which people of certain social relations possess for the purpose of causing people to become its manner through assimilating outstanding culture. The humane education for the undergraduate in technology universities should include humane and social sciences.

We present a theoretical overview of the work process systematization, and then point out the implementation of the curriculum development program and the curriculum teaching process based on the work process. We design, develop and practice the case of "assembly process of electronic products" of mechatronics. At first, we have cooperated with Qingdao Runze Equipment Co., Ltd. and Qingdao Dongfang Huicheng Electronics Co., ltd. We apply the task analysis method to investigate the demand of talents in the enterprises of Mechatronics majors work in, the typical job assignment, typical post ability inquisition, specific job analysis, and research on the vocational and technical qualifications of students, typical task analysis and then determine the field of action based on it. Turning action areas into learning areas (a key part of curriculum development) we design the learning situation of the course, carry on the curriculum teaching organization design, moreover formulate the curriculum examination standard, form a relatively complete curriculum development system based on the work process oriented vocational school curriculum. Then, according to the research results, we develop the "electronic product assembly process" textbook example, and apply it to the teaching practice of specialized courses. We carry out teaching, teaching summary, repeatedly demonstrate, repeatedly revise, and initially completed the connection between the professional courses of electromechanical integration and electronic and electrical engineering job groups docking requirements, and achieve the goal of improving students' professional interest and ability, and enhancing their ability to do their work.

\section{CURRICULUM EVALUATION SHOULD BE DIVERSIFIED}

Curriculum evaluation is an integral part of language teaching and learning. It is characterized by providing honest 
feedbacks about both teaching and learning timely. Therefore students will adjust their learning strategies and teachers will convert their ways of teaching according to honest feedbacks provided by the student formative assessment. We should attention to students' learning subjectivity and their active internalization of knowledge in the process of teaching. Depending on the different level of participation of students in the classroom, the case teaching method is divided into three forms--Discussion-based case teaching, Role-playing type case teaching, Virtual Analog case teaching, in order to enrich the case teaching form and enhance students' interest in learning and improve the level of participation of students in class. The course evaluation should reflect the cooperation of university. and enterprise, linking up teaching education and professional certification. The enterprise should be a good adviser in curriculum design, an assistant in curriculum implementation and a leading role in curriculum evaluation. In terms of optimizing experimental assessment methods, we should diversify the forms, strengthen experimental process, give consideration to the experimental attitude and focus on the experimental report. Then, from the perspective of teacher and students, we use students' study result, learning effect questionnaires, interview and other diversified evaluation methods. Combining qualitative evaluation and quantitative evaluation, the students' learning effect and the application of curriculum reversal teaching are investigated and evaluated.

The guarantee mechanism to promote the curriculum evaluation of school enterprise cooperation is teacher participation mechanism and enterprise participation mechanism. Teacher involvement mechanism refers to establishing sufficient rights, potent encouragement or award, just assessment and effective training mechanism. Enterprise involvement mechanism includes providing the enterprise with a perfect incentive mechanism, an efficient win-win mechanism and a scientific management mechanism. Applied undergraduate university have to build up conditions and atmosphere, stimulate the enthusiasm and initiative of teachers, industry professionals and curriculum experts, and promote their sense of responsibilities, ensuring that they devote themselves to the career of curriculum development[6]. Our school has worked closely with Qingdao Runze Equipment Co., Ltd. and Qingdao Dongfang Huicheng Electronics Co., Ltd., and has put forward some incentive measures to enable both schools and enterprises to participate in the process of personnel training.

Combining the training objectives with the curriculum, we can, on the one hand, reflect the students' comprehensive evaluation of each ability in the final results. On the other hand, the training objectives can be applied to the formative evaluation of the course. Students can adjust by the evaluation of the courses they take each semester, and can increase their expertise in certain ability by taking some courses according to their own interest, which further solve the problem that training objectives cannot be quantified. From the overall, quantitative training goals, through the superposition, can realize the deeper evaluation of the overall ability of the college teaching ability.

\section{SUMMARY}

This paper focuses on the study about the path of the applied undergraduate universities curriculum content development, namely, first of all, it is necessary to determine the main body of the content development of applicationoriented course, mainly including industry \& enterprise practice experts, higher vocational teachers, curriculum experts, college learners and their parents, etc. Following is to determine the structure of applied curriculum content, solve the types of higher education curriculum contents, the arrangement order and the class hour assignment. Next, according to a certain concept of courses and the principles for the selection of curriculum content and the earnest screening to ensure that the courses screened out can satisfy the demand of the society, enterprises and individuals. In addition, it is also important to organize the content of the courses that have been selected, which is the key part to ensure the best optimization of the content of higher college courses. Finally, evaluate the content of the higher education curriculum, and collect feedback information in time, which can provide reference for further revision of the content of higher education courses and the next round of application course content development.

\section{ACKNOWLEDGMENT}

This work was financially supported by the teaching reform research Projects of Vocational Education in Shandong Province(NO:2017549), the teaching reform research Projects of Qingdao Huanghai University(NO:2016jiaoxue06).

\section{REFERENCES}

[1] Liu Zhanwen, Long Shulin.Analysis on the Reform of Integrated Talents Cultivation Model of Newly-built Undergraduate Institutions[J]. Vocational and Technical Education,2013(17):9-12.

[2] Zhang Xiangfeng, Wang Haiqun, Chen Guochu.Revised and Discussion on Automation Major Training and Development Program for Application-typed Undergraduates [J].China Higher Education Research, 2015,(5):5-8.

[3] Fan Caixia.The Technology-oriented Mechanical Engineering Curriculum System Construction for Applied Talents Cultivating [J]. China Modern Educational Equipment,2016(8):57-59.

[4] Sun Aijing, Fan Jiulun, Yang Wujun. Exploration and Practice of Constructing Curriculum System for Applied Talents Training in Local Colleges and Universities[J]. Higher Education Forum,2015(5):59-61

[5] Sun Tongsheng. Teaching Reform for Mechanics Courses for Process Equipment and Control Engineering Based on Made in China 2025 [J]. Journal of Jixi University,2017(3):1-4.

[6] Zhou Cailan. Comparative Research on the Curricular System of Highlevel Applied Talents Based on Occupational Development [J]. Vocational and Technical Education,2014(19):32-37. 